\title{
Dystonia and DBS: The Jury Arrives
}

\author{
Han-Joon Kim and Beom S. Jeon \\ Seoul National University \\ Korea
}

\section{Introduction}

Even before the deep brain stimulation (DBS) era, stereotactic functional neurosurgery such as thalamotomy and pallidotomy had been used for control of medically intractable dystonia (Cooper, 1976; Lozano et al., 1997). However, unreliability and variability in the results and furthermore, needs for bilateral surgery in most patients with generalized dystonia and the occurrence of unacceptable adverse effects including dysarthria and cognitive impairment have greatly limited their use. In this regard, DBS, which provides a more stable response with fewer side effects, has revolutionized the treatment of dystonia. The first report of DBS for dystonia was by Mundinger in 1977 (Mundinger, 1997). Since then, over the past few decades, bilateral globus pallidus internus (GPi) DBS has emerged as the best therapeutic option for medication-refractory dystonia (Lang, 2011).

Generally, bilateral GPi DBS is effective and safe for primary dystonias whether it is generalized or segmental (Bronte-Stewart et al., 2011). However, its effects on secondary dystonias are variable and generally less favorable (Eltahawy et al., 2004).

This Chapter will focus on factors that should be considered before and after DBS in patients with dystonia and the outcome of GPi DBS for the different forms of dystonia.

\section{Mechanism of GPi DBS in dystonia}

Since the pathophysiological mechanism of dystonia is not clearly understood, the mechanism by which GPi DBS improves dystonia remains elusive. The proposed mechanism of GPi DBS involves (1) silencing of stimulated neurons, which results in blocking of the pathological outflow from the target structure (i.e. GPi), and (2) introduction of new activity in the network (Hammond et al., 2008). Neuronal activity is altered in the GPi, thalamic ventral oral posterior nucleus (Vop), and subthalamic nucleus (STN) in dystonia (Zhuang et al., 2004); thus, it is suggested that GPi DBS modulates the activity of GABAergic GPi efferent exons, which inhibits Vop neurons through one or both of the above mentioned mechanisms (Hammond et al., 2008).

\section{General consideration: Presurgical}

\subsection{Patient selection}

When facing a surgical decision, several factors should be taken into account (Volkmann \& Benecke, 2002). First and most important, the diagnosis of dystonia should be correct. It is 
especially true for patients with phasic hyperkinetic movement or patients with dystonic tremor because sometimes very careful evaluation is needed to differentiate these conditions from chorea and tremor disorders, respectively. Second, DBS should be considered only when medical treatment has proven to be ineffective. Third, it should be determined whether the target symptom is the predominant source of the disability and severe enough to do surgery despite its cost and the risk of adverse events. Finally, the patient should have the realistic goals and expectations because not all the dystonic symptoms that the patient has had before surgery will disappear or improve after DBS.

\subsection{Target selection}

GPi is an established and the most commonly used target for DBS in the treatment of dystonia. Many studies have shown that GPi DBS improves motor symptoms and quality of life in patients with medically intractable dystonia.

Recently, several reports showed that STN DBS also improved dystonia and suggested that it may be an alternative target. Bilateral STN DBS improved primary cervical dystonia with an efficacy comparable to that of GPi DBS (Ostrem et al., 2011). Improvements in secondary dystonia such as neurodegeneration with brain iron accumulation (NBIA) also have been reported (Ge et al., 2011; Zhang et al., 2006). Moreover, it has been claimed that STN is a better target than GPi for segmental dystonia because stimulation-related adverse effects such as bradykinesia, which has been repeatedly reported in GPi DBS, does not occur with STN DBS (Ostrem et al., 2011). However, STN is still a novel target for dystonia and further studies are needed to see whether STN DBS is an effective and safe therapy for dystonia. Successful treatment of writer's cramp with thalamic DBS has been reported (Fukaya et al., 2007), but generally, it is not considered as a therapeutic option for dystonia (Andrews et al., 2010).

\section{Primary dystonia}

\subsection{Primary generalized dystonia}

Primary generalized dystonia responds well to GPi DBS. Actually, it is the only form of dystonia, in which, the effect of GPi DBS was confirmed by randomized controlled trials. The mean improvement in the Burke-Fahn-Marsden Dystonia Rating Scale (BFMDRS) movement score was $46 \%$ at 6 months in one study (Kupsch et al., 2006) and 51\% at 1 year and $58 \%$ at 3 year in another study without permanent adverse effects (Vidailhet et al., 2005, 2007). A recent long-term follow-up study showed that improvement by GPi DBS was sustained for up to 8 years (Isaias et al., 2009). Although results from early studies suggested that patients positive for DYT1 mutation have a greater benefit (Coubes et al., 2000; Krauss et al., 2003), it is now widely accepted that there is no difference in the outcome between DYT1-posivie and DYT1-negative patients (Isaias et al., 2008, 2011; Kupsch et al., 2006; Vidailhet et al., 2005). Results from a small group of DYT6-positive patients were less favorable, with 16-55\% of motor improvement (Groen et al., 2010).

The magnitude of response to GPi DBS varies considerably among patients, and factors possibly associated with poor or good outcomes have been suggested. Patients with diffuse phasic hyperkinetic movements tend to improve more rapidly and better than patients with severe tonic posturing (Kupsch et al., 2006; Vidailhet et al., 2005; Wang et al., 2006). Fixed skeletal deformity, longer disease duration at surgery, older age at surgery, and more severe 
motor symptoms at surgery have been associated with a poor outcome (Andrews et al., 2010; Isaias et al., 2008, 2011). Speech and swallowing symptoms are less responsive than axial or limb dystonia (Isaias et al., 2009; Vidailhet et al., 2007), even within an individual patient.

\subsection{Cervical dystonia (spasmodic torticollis)}

Many case reports and several studies indicate that bilateral GPi DBS is an effective treatment for cervical dystonia (Jeong et al., 2009; Kiss et al., 2007; Kupsch et al., 2006; Pretto et al., 2008). Two long-term follow-up studies showed $67 \%$ and $55 \%$ improvement in Toronto Western Spasmodic Torticollis Rating Scale (TWSTRS) severity scores at 38 and 32 months after surgery, respectively (Cacciola et al., 2010; Hung et al., 2007). TWSTRS pain scores were also reduced by more than $50 \%$ and TWSTRS disability score improved by $81 \%$ and $59 \%$.

Usually the age of the patient at surgery is greater in cervical dystonia than in generalized dystonia and DBS in older subjects in their 60s and 70s appears to be safe. Until now, there has been not enough data to prove that the age or duration of disease at surgery affects the outcome in cervical dystonia. However, since a longer duration of disease may run a risk of fixed skeletal deformities, DBS should be considered before these problems occur (BronteStewart et al., 2011).

As described above, a recently study reported that STN DBS improved cervical dystonia with an efficacy comparable to that of GPi DBS (Ostrem et al., 2011).

\subsection{Craniofacial and craniocervical dystonia (Meige syndrome)}

Data from the literature suggest that GPi DBS is an effective and safe treatment for Meige syndrome. Recent case reports with long-term follow-up (1 to 4 years) show sustained improvement in cranio-facio-cervical dystonia by GPi DBS. Improvement in terms of the BFMDRS movement score was $53 \%$ in one report and $82-86 \%$ in the other reports (Ghang et al., 2010; Lyons et al., 2010; Reese et al., 2011; Sako et al., 2011). However, in a recent case series, the effect of GPi DBS on Meige syndrome was variable with some patients having less than 20\% improvement (Limotai et al., 2011). Speech and swallowing did not improve. The authors pointed out that a careful re-examination of the selection criteria for surgery for Meige syndrome is needed.

\section{Secondary dystonia}

\subsection{Myoclonus-dystonia ( $\varepsilon$-Sarcoglycan mutation, DYT11)}

Several case reports showed that bilateral GPi DBS improves motor symptoms in patients with myoclonus-dystonia with an overall improvement of $60 \%$ to $90 \%$ (Cif et al., 2004; Foncke et al., 2007; Jog \& Kumar, 2009; Kurtis et al., 2010). A recent case series of 5 patients with myoclonus-dystonia reported that both myoclonus and dystonia improved with GPi DBS more than $80 \%$ and this improvement was sustained after 15-18 months of follow-up (Azoulay-Zyss et al., 2011). Improvement in myoclonus but not in dystonia by thalamic DBS was reported in 2 cases of myoclonus-dystonia (Kuncel et al., 2009; Trottenberg et al., 2001). 


\subsection{X-linked dystonia parkinsonism (DYT3, 'Lubag')}

In the literature, 5 case reports of GPi DBS on X-linked dystonia parkinsonism are available (Aguilar et al., 2011; Evidente et al., 2007; Martinez-Torres et al., 2009; Oyama et al., 2010; Wadia et al., 2010). All cases showed improvement in dystonia. Of note, dysarthria, oromandibular dystonia, and stridor, which usually show poor response to GPi DBS in primary generalized dystonia, also improved. Interestingly, improvements in dystonia were immediate in all cases. However, the effect on parkinsonism was variable: parkinsonism improved in 3 patients but not in the other 2 patients.

\subsection{Rapid-onset dystonia parkinsonism (ATA1A3 mutation, DYT12)}

Only 2 case reports of bilateral GPi DBS in this rare disease are available. One patient did not receive any benefit from the surgery (Deutschländer et al., 2005) and the other patient had only mild (30\%) improvement in dystonia, mainly in the craniocervical and truncal area. Limb dystonia and parkinsonism did not improve (Kamm et al., 2008).

\subsection{Tardive dystonia}

DBS is a very effective treatment for tardive dyskinesia. Recent studies showed that GPi DBS improves tardive dystonia motor symptoms for more than $80 \%$ and this benefit was sustained during long-term follow-up up to 80 months (Capelle et al., 2010; Gruber et al., 2009; Trottenberg et al., 2005). In contrast to primary generalized dystonia, patients experienced distinct improvement within days or even hours after stimulation. Improvements of tardive dystonia with STN DBS also have been reported (Sun et al., 2007; Zhang et al., 2006).

\subsection{NBIA}

Responses to GPi DBS are variable in NBIA. There are reports of favorable (65-91\%) responses (Castelnau et al., 2005; Clement et al., 2007; Krause et al., 2006; Mikati et al., 2009; Umemura et al., 2004), but others reported only 20-30\% improvement (Isaac et al., 2007; Shields et al., 2007). A single case report of STN DBS on a NBIA patient showed $84 \%$ improvement at 3 years after surgery (Ge et al., 2011). It is surprising that motor symptoms in NBIA can improve with DBS, given that structural abnormalities in the brain MRI usually meet the exclusion criteria for DBS in primary dystonia (Kupsch et al., 2006; Vidailhet et al., 2005).

\subsection{Cerebral palsy}

A wide range of responses has been reported on the effect of GPi DBS in cerebral palsy. Some patients had favorable outcomes but others experienced no or only minimal improvement (Alterman and Tagliati, 2007; Pretto et al., 2008; Zorzi et al., 2005). This variability in response is most likely due to the heterogeneity of this condition. Recently, a multicenter prospective study investigating the effect of bilateral GPi DBS on dystoniachoreoathetosis cerebral palsy showed $24 \%$ improvement in the BFMDRS movement score at 1 year after surgery (Vidailhet et al., 2009). However, as the authors mentioned, cerebral palsy patients who meet the criteria of this study (i.e. prominent dystonia-choreoathetosis, little or no spasticity, unimpaired intellectual function, and only slight abnormalities of the basal ganglia on MRI) was only about $10 \%$ of the cerebral palsy population. 


\subsection{Other secondary dystonias}

There are many causes of secondary dystonias and the number of patients with each secondary dystonia who underwent DBS is small. There are reports of DBS in postanoxic dystonia, postencephalitic dystonia, and posttraumatic dystonia (Eltahawy et al., 2004; Pretto et al., 2008; Katsakiori et al., 2009; Zhang et al., 2006; Krause et al., 2004; Ghika et al., 2002). Improvements in dystonia in Lesch-Nyhan syndrome (Cif et al., 2007; Pralong et al., 2005) and GM1 gangliosidosis (Roze et al., 2006) also have been reported. Generally, the effects of DBS on secondary dystonias are variable and less favorable.

\section{Task-specific dystonias}

For writer's cramp, contralateral unilateral thalamic DBS has been tried with favorable results (Cho et al., 2009; Fukaya et al., 2007). Improvements were immediate in all cases. It appears that thalamic DBS is more effective than GPi DBS for writer's cramp (Fukaya et al., 2007).

\section{Complications}

There is no compelling evidence that DBS surgery- or device-related adverse effects are more common in dystonia than in Parkinson disease (PD). However, it has been suggested that lead migration and lead fracture is more common in dystonia than in parkinsonian patients (Yianni et al., 2003). Stimulation-related adverse effects specific for GPi DBS in dystonia include the development of reversible bradykinesia and parkinsonian gait problems in previously nondystonic body regions (Berman et al., 2009; Ostrem et al., 2007; Zauber et al., 2009).

\section{Postsurgical management}

Several points should be kept in mind when managing dystonic patients after DBS surgery (Kupsch et al., 2011).

In contrast to PD where maximal clinical effect of DBS occurs within hours of switching on of the device, the beneficial effects of DBS in dystonia are not immediate and slowly progress over weeks to months, possibly beyond 1 year after surgery. This protracted improvement is more prominent in older patients (Isaias et al., 2011). There is no evidence that tolerance develops with long-term stimulation (Tagliati et al., 2011).

Battery lifetime in GPi DBS for dystonia is usually shorter compared to that in DBS for PD because of higher voltages and greater pulse widths. Thus, a more frequent battery change is required. In a recent study, the mean battery life in patients with GPi DBS for dystonia was 25 months (Blahak et al., 2011). Regarding inadvertent depletion of the battery or discontinuation of stimulation during procedures for battery replacement, it should be noted that sudden bilateral cessation of stimulation can lead to acute and possibly life threatening rebound dystonia or respiratory difficulty (Grabli et al., 2009; Tagliati et al., 2011).

\section{Conclusion}

So, has the jury arrived at a verdict as to the usefulness of DBS in treatment of dystonia? The answer appears to be yes for primary dystonias. However, for secondary dystonias, more evidences are needed. 
Literatures show that bilateral GPi DBS is an effective and safe therapy for medically intractable primary dystonia and it provides a sustained benefit. Not only good surgical technique, but also appropriate selection of patients and individualized postsurgical management are crucial for optimized patient care.

In secondary dystonias, its effects are heterogeneous, and at this stage, data are not enough to determine whether it can be considered as an effective therapy for each form of the disease. Further studies are needed for re-examination of the inclusion criteria and selection of targets other than GPi.

\section{References}

Aguilar JA, Vesagas TS, Jamora RD et al. (2011). The promise of deep brain stimulation in Xlinked dystonia parkinsonism. Int J Neurosci. Vol.121, pp.57-63, ISSN 0020-7454

Alterman RL \& Tagliati M. (2007). Deep brain stimulation for torsion dystonia in children. Child's Nervous System. Vol.23, pp.1033-1040, ISSN 0256-7040

Andrews C, Aviles-Olmos I, Hariz M et al. (2010). Which patients with dystonia benefit from deep brain stimulation? A metaregression of individual patient outcomes. Journal of Neurology, Neurosurgery \& Psychiatry. Vol.81, pp.1383-1389, ISSN 00223050

Azoulay-Zyss J, Roze E, Welter ML et al. (2011). Bilateral Deep Brain Stimulation of the Pallidum for Myoclonus-Dystonia Due to -Sarcoglycan Mutations: A Pilot Study. Archives of neurology. Vol.68, pp.94-98, ISSN 0003-9942

Berman BD, Starr PA, Marks Jr WJ et al. (2009). Induction of bradykinesia with pallidal deep brain stimulation in patients with cranial-cervical dystonia. Stereotact Funct Neurosurg. Vol.87, pp.37-44, ISSN 1011-6125

Blahak C, Capelle HH, Baezner $\mathrm{H}$ et al. (2011). Battery lifetime in pallidal deep brain stimulation for dystonia. European Journal of Neurology. Vol.18, pp.872-875, ISSN 1468-1331

Bronte-Stewart H, Taira T, Valldeoriola F et al. (2011). Inclusion and exclusion criteria for DBS in dystonia. Movement disorders. Vol. 26, pp.S5-S16, ISSN 0885-3185

Cacciola F, Farah JO, Eldridge PR et al. (2010). Bilateral Deep Brain Stimulation for Cervical Dystonia: Long-term Outcome in a Series of 10 Patients. Neurosurgery. Vol.67, pp.957-963, ISSN 0148-396X

Capelle HH, Blahak C, Schrader C et al. (2010). Chronic deep brain stimulation in patients with tardive dystonia without a history of major psychosis. Movement disorders. Vol.25, pp.1477-1481, ISSN 0885-3185

Castelnau P, Cif L, Valente EM et al. (2005). Pallidal stimulation improves pantothenate kinase-associated neurodegeneration. Annals of neurology. Vol.57, pp738-741, ISSN 0364-5134

Cho CB, Park HK, Lee KJ et al. (2009). Thalamic deep brain stimulation for writer's cramp. Journal of Korean Neurosurgical Society. Vol.46, pp52-55, ISSN 2005-3711

Cif L, Biolsi B, Gavarini S et al. (2007). Antero ventral internal pallidum stimulation improves behavioral disorders in Lesch-Nyhan disease. Movement disorders. Vol.22, pp.2126-2129, ISSN 0885-3185

Cif L, Valente EM, Hemm S et al. (2004). Deep brain stimulation in myoclonus-dystonia syndrome. Movement disorders. Vol.19, pp.724-727, ISSN 0885-3185 
Clement F, Devos D, Moreau C et al. (2007). Neurodegeneration with brain iron accumulation: clinical, radiographic and genetic heterogeneity and corresponding therapeutic options. Acta neurologica belgica. Vol.107, pp.26-31, ISSN 0300-9009

Cooper IS. (1976). 20-year followup study of the neurosurgical treatment of dystonia musculorum deformans. Advances in neurology. Vol.14, pp.423-452, ISSN 0091-3952

Coubes P, Roubertie A, Vayssiere N et al. (2000). Treatment of DYT1-generalised dystonia by stimulation of the internal globus pallidus. The Lancet. Vol.355, pp.2220-2221, ISSN 0140-6736

Deutschländer A, Asmus F, Gasser T et al. (2005). Sporadic rapid onset dystoniaparkinsonism syndrome: Failure of bilateral pallidal stimulation. Movement disorders. Vol.20, pp.254-257, ISSN 0885-3185

Eltahawy HA, Saint-Cyr J, Giladi N et al. (2004). Primary dystonia is more responsive than secondary dystonia to pallidal interventions: outcome after pallidotomy or pallidal deep brain stimulation. Neurosurgery. Vol.54, pp613-619, ISSN 0148-396X

Evidente VGH, Lyons MK, Wheeler M et al. (2007). First case of X linked dystonia parkinsonism ("Lubag") to demonstrate a response to bilateral pallidal stimulation. Movement disorders. Vol.22, pp1790-1793, ISSN 0885-3185

Foncke EMJ, Bour LJ, Speelman JD et al. (2007). Local field potentials and oscillatory activity of the internal globus pallidus in myoclonus-dystonia. Movement disorders. Vol.22, pp369-376, ISSN 0885-3185

Fukaya C, Katayama Y, Kano T et al. (2007). Thalamic deep brain stimulation for writer's cramp. Journal of Neurosurgery: Pediatrics. Vol.107, pp.977-982, ISSN 1933-0707

Ge M, Zhang K, Ma Y et al. (2011). Bilateral Subthalamic Nucleus Stimulation in the Treatment of Neurodegeneration with Brain Iron Accumulation Type 1. Stereotactic and Functional Neurosurgery. Vol.89, pp.162-166, ISSN 1011-6125

Ghang JY, Lee MK, Jun SM, Ghang CG. (2010). Outcome of pallidal deep brain stimulation in meige syndrome. Journal of Korean Neurosurgical Society. Vol.48, pp.134-138, ISSN 2005-3711

Ghika J, Villemure J, Miklossy J et al. (2002). Postanoxic generalized dystonia improved by bilateral Voa thalamic deep brain stimulation. Neurology. Vol.58, pp311-313, ISSN 0028-3878

Grabli D, Ewenczyk C, Coelho Braga MC et al. (2009). Interruption of deep brain stimulation of the globus pallidus in primary generalized dystonia. Movement disorders. Vol.24, pp2363-2369, ISSN 0885-3185

Groen JL, Ritz K, Contarino MF et al. (2010). DYT6 dystonia: Mutation screening, phenotype, and response to deep brain stimulation. Movement disorders. Vol.25, pp.2420-2427, ISSN 0885-3185

Gruber D, Trottenberg T, Kivi A et al. (2009). Long-term effects of pallidal deep brain stimulation in tardive dystonia. Neurology. Vol.73, pp.53-58, ISSN 0028-3878

Hammond C, Ammari R, Bioulac B et al. (2008). Latest view on the mechanism of action of deep brain stimulation. Movement disorders. Vol.23, pp.2111-2121, ISSN 0885-3185

Hung S, Hamani C, Lozano A et al. (2007). Long-term outcome of bilateral pallidal deep brain stimulation for primary cervical dystonia. Neurology. Vol.68, pp.457-459, ISSN 0028-3878 
Isaac C, Wright I, Bhattacharyya D et al. (2008). Pallidal stimulation for pantothenate kinaseassociated neurodegeneration dystonia. Archives of disease in childhood. Vol.93, pp.239-240, ISSN 0003-9888

Isaias IU, Alterman RL, Tagliati M. (2008). Outcome predictors of pallidal stimulation in patients with primary dystonia: the role of disease duration. Brain. Vol.131, pp.1895-1902, ISSN 0006-8950

Isaias IU, Alterman RL, Tagliati M. (2009). Deep brain stimulation for primary generalized dystonia: long-term outcomes. Archives of neurology. Vol.66, pp.465-470, 0003-9942

Isaias IU, Volkmann J, Kupsch A et al. Factors predicting protracted improvement after pallidal DBS for primary dystonia: the role of age and disease duration. Journal of Neurology. DOI 10.1007/s00415-011-5961-9, ISSN 0340-5354

Jeong SG, Lee MK, Kang JY et al. (2009). Pallidal deep brain stimulation in primary cervical dystonia with phasic type: clinical outcome and postoperative course. Journal of Korean Neurosurgical Society. Vol.46, pp346-350, ISSN 2005-3711

Jog M \& Kumar H. (2009). Bilateral pallidal deep brain stimulation in a case of myoclonus dystonia syndrome. Movement disorders. Vol.24, pp1547-1549, ISSN 0885-3185

Kamm C, Fogel W, Wachter T et al. (2008). Novel ATP1A3 mutation in a sporadic RDP patient with minimal benefit from deep brain stimulation. Neurology. Vol.70, pp1501-1503, ISSN 0028-3878

Katsakiori P, Kefalopoulou Z, Markaki E et al. (2009). Deep brain stimulation for secondary dystonia: results in 8 patients. Acta Neurochirurgica. Vol.151, pp473-478, ISSN 00016268

Kiss ZHT, Doig-Beyaert K, Eliasziw M et al. (2007). The Canadian multicentre study of deep brain stimulation for cervical dystonia. Brain. Vol.130, pp2879-2886, ISSN 0006-8950

Krause M, Fogel W, Kloss M et al. (2004). Pallidal stimulation for dystonia. Neurosurgery. Vol.55, pp.1361-1370, ISSN 0148-396X

Krause M, Fogel W, Tronnier V et al. (2006). Long term benefit to pallidal deep brain stimulation in a case of dystonia secondary to pantothenate kinase associated neurodegeneration. Movement disorders. Vol.21, pp2255-2257, ISSN 0885-3185

Krauss JK, Loher TJ, Weigel R et al. (2003). Chronic stimulation of the globus pallidus internus for treatment of non-dYT1 generalized dystonia and choreoathetosis: 2year follow up. Journal of neurosurgery. Vol.98, pp785-792, ISSN 0022-3085

Kuncel AM, Turner DA, Ozelius LJ et al. (2009). Myoclonus and tremor response to thalamic deep brain stimulation parameters in a patient with inherited myoclonus-dystonia syndrome. Clinical neurology and neurosurgery. Vol.111, pp.303-306, ISSN 0303-8467

Kupsch A, Benecke R, Müller J et al. (2006). Pallidal Deep-Brain Stimulation in Primary Generalized or Segmental Dystonia. New England Journal of Medicine. Vol.355, pp1978-1990, ISSN 0028-4793

Kupsch A, Tagliati M, Vidailhet M et al. (2011). Early postoperative management of DBS in dystonia: programming, response to stimulation, adverse events, medication changes, evaluations, and troubleshooting. Movement disorders. Vol. 26, pp.S41-S57, ISSN 0885-3185

Kurtis MM, San Luciano M, Yu Q et al. (2010). Clinical and neurophysiological improvement of SGCE myoclonus-dystonia with GPi deep brain stimulation. Clinical neurology and neurosurgery. Vol.112, pp149-152, ISSN 0303-8467 
Lang AE. (2011). Deep brain stimulation for dystonia. Movement disorders. Vol. 26, pp.S43-S4, ISSN 0885-3185

Limotai N, Go C, Oyama G et al. Mixed results for GPi-DBS in the treatment of cranio-facial and cranio-cervical dystonia symptoms. Journal of Neurology. DOI: 10.1007/s00415011-6075-0, ISSN 0340-5354

Lozano AM, Kumar R, Gross R et al. (1997). Globus pallidus internus pallidotomy for generalized dystonia. Movement disorders. Vol.12, pp865-870, ISSN 0885-3185

Lyons MK, Birch BD, Hillman RA et al. (2010). Long-term follow-up of deep brain stimulation for Meige syndrome. Neurosurgical focus. Vol.29, p.E5, ISSN 1092-0684

Martinez Torres I, Limousin P, Tisch S et al. (2009). Early and marked benefit with GPi DBS for Lubag syndrome presenting with rapidly progressive life threatening dystonia. Movement disorders. Vol.24, pp.1710-1712, ISSN 0885-3185

Mikati MA, Yehya A, Darwish H et al. (2009). Deep brain stimulation as a mode of treatment of early onset pantothenate kinase-associated neurodegeneration. European Journal of Paediatric Neurology. Vol.13, pp.61-64, ISSN 1090-3798

Mundinger F. (1977). Neue stereotaktisch-functionelle Behandlungsmethode des Torticollis spasmodicus mit Hirn-stimulatoren. Medizinische Klinik. Vol.72, pp.1982-1987, ISSN 0025-8458

Ostrem JL, Marks Jr WJ, Volz MM et al. (2007). Pallidal deep brain stimulation in patients with cranial-cervical dystonia (Meige syndrome). Movement disorders. Vol.22, pp.1885-1891, ISSN 0885-3185

Ostrem JL, Racine CA, Glass GA et al. (2011). Subthalamic nucleus deep brain stimulation in primary cervical dystonia. Neurology. Vol.76, pp.870-878, ISSN 0028-3878

Oyama G, Fernandez HH, Foote KD et al. (2010). Differential Response of Dystonia and Parkinsonism following Globus Pallidus Internus Deep Brain Stimulation in XLinked Dystonia-Parkinsonism (Lubag). Stereotactic and Functional Neurosurgery. Vol.88, pp329-333, ISSN 1011-6125

Pralong E, Pollo C, Coubes P et al. (2005). Electrophysiological characteristics of limbic and motor globus pallidus internus (GPI) neurons in two cases of Lesch-Nyhan syndrome. Clinical Neurophysiology. Vol.35, pp.168-173, ISSN 1388-2457

Pretto TE, Dalvi A, Kang UJ, Penn RD. (2008). A prospective blinded evaluation of deep brain stimulation for the treatment of secondary dystonia and primary torticollis syndromes. Journal of Neurosurgery: Pediatrics. Vol.109, pp.405-409, ISSN 1933-0707

Reese R, Gruber D, Schoenecker T et al. (2011). Long term clinical outcome in Meige syndrome treated with internal pallidum deep brain stimulation. Movement disorders. Vol.26, pp.691-698, ISSN 0885-3185

Roze E, Navarro S, Cornu P et al. (2006). Deep brain stimulation of the globus pallidus for generalized dystonia in GM1 Type 3 gangliosidosis: technical case report. Neurosurgery. Vol.59, p.E1340, ISSN 0148-396X

Sako W, Morigaki R, Mizobuchi Y et al. (2011). Bilateral pallidal deep brain stimulation in primary Meige syndrome. Parkinsonism \& Related Disorders. Vol.17, pp.123-125, ISSN 1353-8020

Shields DC, Sharma N, Gale JT, Eskandar EN. (2007). Pallidal stimulation for dystonia in pantothenate kinase-associated neurodegeneration. Pediatric neurology. Vol. 37, pp.442-445, ISSN 0887-8994 
Sun B, Chen S, Zhan S et al. (2007). Subthalamic nucleus stimulation for primary dystonia and tardive dystonia. Acta Neurochirurgica Supplementum. Vol.97 pp.207-214, ISSN 0065-1419

Tagliati M, Krack P, Volkmann J et al. (2011). Long Term management of DBS in dystonia: Response to stimulation, adverse events, battery changes, and special considerations. Movement disorders. Vol.26, pp.S54-S62, ISSN 0885-3185

Trottenberg T, Meissner W, Arnold G et al. (2001). Neurostimulation of the ventral intermediate thalamic nucleus in inherited myoclonus dystonia Syndrome. Movement disorders. Vol.16, pp769-771, ISSN 0885-3185

Trottenberg T, Volkmann J, Deuschl G et al. (2005). Treatment of severe tardive dystonia with pallidal deep brain stimulation. Neurology. Vol.64, pp.344-346, ISSN 0028-3878

Umemura A, Jaggi JL, Dolinskas CA et al. (2004). Pallidal deep brain stimulation for longstanding severe generalized dystonia in Hallervorden-Spatz syndrome. Journal of neurosurgery. Vol.100, p706-709, ISSN 0022-3085

Vidailhet M, Vercueil L, Houeto J et al. Bilateral deep-brain stimulation of the globus pallidus in primary generalized dystonia. N Engl J Med. 2005;352:459-467, ISSN 0028-4793

Vidailhet M, Vercueil L, Houeto JL et al. (2007). Bilateral, pallidal, deep-brain stimulation in primary generalised dystonia: a prospective 3 year follow-up study. The Lancet Neurology. Vol.6, pp.223-229, ISSN 1474-4422

Vidailhet M, Yelnik J, Lagrange C et al. (2009). Bilateral pallidal deep brain stimulation for the treatment of patients with dystonia-choreoathetosis cerebral palsy: a prospective pilot study. The Lancet Neurology. Vol.8, pp.709-717, ISSN 1474-4422

Volkmann J and Benecke R. (2002). Deep brain stimulation for dystonia: patient selection and evaluation. Movement disorders. Vol.17, pp.S112-S115, ISSN 0885-3185

Wadia PM, Lim SY, Lozano AM et al. (2010). Bilateral pallidal stimulation for $x$-linked dystonia parkinsonism. Archives of neurology. Vol.67, pp.1012-1015, ISSN 0003-9942

Wang S, Liu X, Yianni J et al. (2006). Use of surface electromyography to assess and select patients with idiopathic dystonia for bilateral pallidal stimulation. Journal of neurosurgery. Vol.105, pp.21-25, ISSN 0022-3085

Yianni J, Nandi D, Shad A et al. (2004). Increased risk of lead fracture and migration in dystonia compared with other movement disorders following deep brain stimulation. Journal of Clinical Neuroscience. Vol.11, pp.243-245, ISSN 0967-5868

Zauber SE, Watson N, Comella CL et al. (2009). Stimulation-induced parkinsonism after posteroventral deep brain stimulation of the globus pallidus internus for craniocervical dystonia. Journal of neurosurgery. Vol.110, pp.229-233, ISSN 0022-3085

Zhang J, Zhang K, Wang Z et al. (2006). Deep brain stimulation in the treatment of secondary dystonia. Chinese medical journal. Vol.119, pp.2069-2074, ISSN 0366-6999

Zhuang P, Li Y, Hallett M. (2004). Neuronal activity in the basal ganglia and thalamus in patients with dystonia. Clinical Neurophysiology. Vol.115, pp.2542-2557, ISSN 13882457

Zorzi G, Marras C, Nardocci N et al. (2005). Stimulation of the globus pallidus internus for childhood onset dystonia. Movement disorders. Vol.20, pp.1194-1200, ISSN 0885-3185 


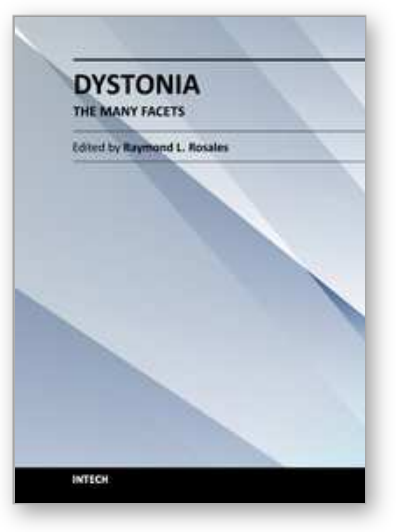

\author{
Dystonia - The Many Facets \\ Edited by Prof. Raymond Rosales
}

ISBN 978-953-51-0329-5

Hard cover, 220 pages

Publisher InTech

Published online 14, March, 2012

Published in print edition March, 2012

Dystonia has many facets, and among those, this book commences with the increasingly associated genes identified, including a construct on how biology interacts with the dystonia genesis. The clinical phenomenology of dystonia as approached in the book is interesting because, not only were the cervical, oromandibular/lingual/laryngeal, task-specific and secondary dystonias dealt with individually, but that the associated features such as parkinsonism, tremors and spasticity were also separately presented. Advances in dystonia management followed, and they ranged from dopaminergic therapy, chemodenervation, surgical approaches and rehabilitation, effectively complementing the approach in dystonia at the clinics. A timely critical pathophysiologic review, including the muscle spindle involvement in dystonia, is highlighted at the book's end.

\title{
How to reference
}

In order to correctly reference this scholarly work, feel free to copy and paste the following:

Han-Joon Kim and Beom S. Jeon (2012). Dystonia and DBS: The Jury Arrives, Dystonia - The Many Facets, Prof. Raymond Rosales (Ed.), ISBN: 978-953-51-0329-5, InTech, Available from:

http://www.intechopen.com/books/dystonia-the-many-facets/dystonia-and-dbs-the-jury-arrives

\section{INTECH}

open science | open minds

\section{InTech Europe}

University Campus STeP Ri

Slavka Krautzeka 83/A

51000 Rijeka, Croatia

Phone: +385 (51) 770447

Fax: +385 (51) 686166

www.intechopen.com

\section{InTech China}

Unit 405, Office Block, Hotel Equatorial Shanghai

No.65, Yan An Road (West), Shanghai, 200040, China

中国上海市延安西路65号上海国际贵都大饭店办公楼405单元

Phone: +86-21-62489820

Fax: +86-21-62489821 
(C) 2012 The Author(s). Licensee IntechOpen. This is an open access article distributed under the terms of the Creative Commons Attribution 3.0 License, which permits unrestricted use, distribution, and reproduction in any medium, provided the original work is properly cited. 